\title{
The Absorption of Light in Lakes: Negative Impact of Dissolved Organic Carbon on Primary Productivity
}

\author{
Jan-Erik Thrane, ${ }^{1,2}$ Dag O. Hessen, ${ }^{1,2}$ and Tom Andersen ${ }^{2 *}$
}

\begin{abstract}
${ }^{1}$ Centre for Ecological and Evolutionary Synthesis (CEES), Department of Biosciences, University of Oslo, Blindern, P.O. Box 1066, 0316 Oslo, Norway; ${ }^{2}$ Section for Aquatic Biology and Toxicology (AKVA), Department of Biosciences, University of Oslo, Blindern, P.O. Box 1066, 0316 Oslo, Norway
\end{abstract}

\begin{abstract}
Colored dissolved organic matter (CDOM) absorbs a substantial fraction of photosynthetically active radiation (PAR) in boreal lakes. However, few studies have systematically estimated how this light absorption influences pelagic primary productivity. In this study, 75 boreal lakes spanning wide and orthogonal gradients in dissolved organic carbon (DOC) and total phosphorus (TP) were sampled during a synoptic survey. We measured absorption spectra of phytoplankton pigments, $\mathrm{CDOM}$, and non-algal particles to quantify the vertical fate of photons in the PAR region. Area-specific rates of gross primary productivity $\left(\mathrm{PP}_{\mathrm{A}}\right)$ were estimated using a bio-optical approach based on phytoplankton in vivo light absorption and the light-dependent quantum yield of photochemistry in PSII measured by a PAM fluorometer. Subsequently, we calculated the effects of CDOM, DOC,
\end{abstract}

\section{INTRODUCTION}

The concentrations of dissolved organic carbon (DOC) in boreal lakes have increased over the past

Received 17 December 2013; accepted 23 April 2014; published online 28 May 2014

Author Contributions: TA conceived and designed the study, JET, TA, and DOH performed field work, JET performed laboratory work, JET and TA analyzed the data, JET, DOH, and TA wrote the paper.

*Corresponding author; e-mail: tom.andersen@ibv.uio.no and TP concentration on $\mathrm{PP}_{\mathrm{A}}$. CDOM absorbed the largest fraction of PAR in the majority of lakes (mean $56.3 \%$, range $36.9-76.2 \%$ ), phytoplankton pigments captured a comparatively minor fraction (mean $6.6 \%$, range $2.2-28.2 \%$ ). $\mathrm{PP}_{\mathrm{A}}$ estimates spanned from 45 to $993 \mathrm{mg} \mathrm{C} \mathrm{m}^{-2}$ day $^{-1}$ (median $286 \mathrm{mg} \mathrm{C} \mathrm{m}^{-2}$ day $\left.{ }^{-1}\right)$. We found contrasting effects of CDOM (negative) and TP (positive) on $\mathrm{PP}_{\mathrm{A}}$. The use of DOC or CDOM as predictors gave very similar results and the negative effect of these variables on $\mathrm{PP}_{\mathrm{A}}$ can probably be attributed to shading. A future scenario of increased DOC, which is highly correlated with CDOM in these lakes, might impose negative effects on areal primary productivity in boreal lakes.

Key words: light absorption; lakes; DOC; CDOM; primary productivity; photosynthesis. two decades in many regions (Skjelkvåle and others 2005; Evans and others 2006). Reduced acid deposition (Monteith and others 2007), increased temperature (Weyhenmeyer and Karlsson 2009), precipitation, and vegetation cover (Larsen and others 2011c) are all proposed as driving forces behind this trend. DOC is predicted to continue increasing also in the future because of higher export from catchments to lakes (Larsen and others $2011 a)$. 
Colored dissolved organic matter (CDOM) is a controlling factor for light attenuation in boreal lakes (Kirk 2011) and is highly correlated with DOC concentration (Tranvik 1990 and this paper). This is because the molecules constituting DOC have strong chromophoric properties (Leenheer and Croue 2003). Notably, there is significant variation in specific DOC absorption [that is, $\left.\mathrm{m}^{2}(\mathrm{mg} \mathrm{DOC})^{-1}\right]$. Some of this variation can be explained by iron, which recently has received increased attention in the context of lake browning (Weyhenmeyer and others 2014). Due to the strong light-absorbing properties of CDOM, one might hypothesize primary productivity $(\mathrm{PP})$ to be negatively related to CDOM in lakes because a large fraction of the photosynthetically active radiation (PAR) would be absorbed by compounds other than the photoautotrophs (Jones 1992; Williamson and Morris 1999). In addition, the spectral absorption coefficients of CDOM increase exponentially toward shorter wavelengths of the PAR spectrum and eventually into the UV-region (Bricaud and others 1981). The degree of shading by these compounds is therefore expected to be most important in the blue part of the PAR spectrum (400-500 nm); wavelengths that coincide with peak absorption for important photosynthetic pigments like chlorophylls and light-harvesting carotenoids (Kirk 1976). This makes it plausible that high concentrations of CDOM or DOC might constrain PP and enhance the net heterotrophy and high rate of $\mathrm{CO}_{2}$-emission from boreal lakes (Cole and others 2000; Larsen and others $201 \mathrm{lb}$ ).

Although the hypothesis of reduced productivity due to CDOM seems to hold true for benthic PP in shallow lakes (Karlsson and others 2009) and for pelagic PP in small lakes (Carpenter and others 1998), clear evidence over large spatial scales is sparse. One reason for this is the difficulty of obtaining data from lakes where CDOM and other factors that control PP, such as total phosphorus (TP), vary independently. In this study, we present data on PP and light absorption properties from 75 large lakes explicitly chosen to span wide and orthogonal gradients in DOC and TP concentrations. Due to the large sample size and geographical range $\left(12^{\circ}\right.$ longitude) it would have been impossible to carry out integrated PP measurements using the standard ${ }^{14} \mathrm{C}$-method (Steemann-Nielsen 1952). To overcome this challenge, we estimated areal $\mathrm{PP}\left(\mathrm{PP}_{\mathrm{A}}\right)$ using a bio-optical approach and estimated the net effects of CDOM, DOC, and TP on these estimates.

The bio-optical model is based on estimating the in vivo rate of light absorption by phytoplankton and subsequently electron transport rates (ETRs) through photosystem II (PSII) using information about the light-dependent quantum yield of photochemistry in PSII (Genty and others 1989). The latter being measured using a pulse amplitude modulated (PAM) fluorometer. ETR can further be converted to a rate of gross carbon fixation by assuming an appropriate value for the quantum yield of $\mathrm{CO}_{2}$ fixation (Kromkamp and Forster 2003; Suggett and others 2010). Bio-optical approaches have gained increased interest over the last two decades because they offer a fast and inexpensive way of obtaining PP estimates, thus potentially increasing the temporal and spatial coverage of productivity studies in both marine and limnetic systems (Kromkamp and Forster 2003). In addition, these measurements provide estimates of gross PP and circumvent some of the constraints associated with the standard ${ }^{14} \mathrm{C}$-method such as bottle effects, uncertainty whether the method measures net or gross PP, and in the extrapolation of in situ incubations in depth and time (Peterson 1980; Wilhelm and others 2004). There are, however, drawbacks to the method in that it actually measures ETR through PSII and therefore is most closely related to gross $\mathrm{O}_{2}$ production (Lawrenz and others 2013). $\mathrm{CO}_{2}$ fixation is assumed to be proportional to ETR, and there are in fact several studies supporting this assumption for both microalgae (Gilbert and others 2000; Masojídek and others 2001; Kromkamp and others 2008) and higher plants (Genty and others 1989). The slope of the C-fixation versus ETR relationship (mol CO$_{2}$ (mol electrons) ${ }^{-1}$ ) is, however, variable and depends on environmental conditions and taxonomic composition (Suggett and others 2010; Lawrenz and others 2013). This, of course, adds a layer of uncertainty to the absolute values of Cfixation, but should not introduce systematic errors along a gradient in, for example, DOC. Therefore, we believe that the method is suited for comparing effects of environmental variables such as DOC and $\mathrm{TP}$ on $\mathrm{PP}_{\mathrm{A}}$.

\section{Materials ANd Methods}

\section{Selection of Lakes}

We combined existing databases of Norwegian and Swedish lake monitoring data [REBECCA (Solheim and others 2008) and the Northern European lake survey (Henriksen and others 1998)] to generate a subset of lakes satisfying the following criteria: latitude $57-64^{\circ} \mathrm{N}$, altitude $<600 \mathrm{~m}$, surface area $>1 \mathrm{~km}^{2}, \mathrm{pH}>5, \quad \mathrm{TP}<30 \mu \mathrm{g} \mathrm{l}^{-1}$, and DOC 
$<30 \mathrm{mg} \mathrm{l}^{-1}$. The selection was made to obtain a set of similarly large lakes that covered a wide and rather orthogonal span in TP and DOC along a narrow altitudinal and latitudinal range, avoiding acidic, eutrophic, and highly dystrophic localities. From this subset, we chose 77 lakes by stratified randomization to ensure best possible coverage and orthogonality with respect to concentrations of DOC and TP. We sampled the lakes using a hydroplane during July and August 2011. Two lakes had to be omitted from the original sample set due to instrumental failure, giving a final dataset of 75 lakes.

\section{Sampling Program}

Composite samples ( $15 \mathrm{l}$ in total) from the surface to $5 \mathrm{~m}$ were taken with an integrating water sampler (Hydro-BIOS, Germany) in the central part of each lake during daytime. We measured vertical attenuation of scalar irradiance in the PAR region (400-700 nm, defined as $E_{0}$ hereafter) using a spherical irradiance sensor (BioSpherical instruments, San Diego, California, USA) attached to a 10-channel CTD profiler (XRX-620, RBR Ltd., Ottawa, ON, Canada). The sensor was deployed at approximately $20 \mathrm{~cm} \mathrm{~s}^{-1}$ with a sampling rate of $6 \mathrm{~Hz}$. To avoid shading from the hydroplane, we always lowered the CTD at the side facing the sun. Vertical profiles of relative in vivo chlorophyll $a$ fluorescence (Cyclops-7 fluorometer, Turner designs, Sunnyvale, California, USA) were recorded to assess vertical distribution of phytoplankton.

\section{$K_{\mathrm{d}} \mathrm{PAR}$ and Daily Insolation}

We corrected the vertical profiles of $E_{0}$ for temporal changes in irradiance (caused by, for example, wave action and cloud cover) by regressing logtransformed $E_{0}(z)$ against depth for every ten sampling points. The median of these slopes was taken as the best estimate of the diffuse attenuation coefficient for downwelling PAR $\left(K_{\mathrm{d}} \mathrm{PAR}\right)$.

For the PP calculations, we needed representative values of incoming solar irradiance at the lakes at the time of sampling. Consequently, we downloaded spatially resolved estimates of accumulated monthly irradiance in the PAR region $\left(E\left(\mathrm{PAR}, 0^{+}\right)\right.$; mol photons $\mathrm{m}^{-2}$ month $^{-1}$ from July 2011) from the STRÅNG database (http://strang.smhi.se/). The data covered Norway and Sweden and irradiances were interpolated to the geographical coordinates of each lake. Mean daily irradiance $\left(E\left(\mathrm{PAR}, 0^{+}\right)\right.$; mol photons $\mathrm{m}^{-2}$ day $\left.^{-1}\right)$ was calculated from the accumulated monthly values. We then modeled the diurnal variation in $E\left(\mathrm{PAR}, \mathrm{O}^{+}\right)$ between sunrise and sunset using a sine function suggested by Kirk (2011):

$$
E\left(\mathrm{PAR}, 0^{+}, t\right)=E_{\max } \sin \left(\frac{\pi t}{N}\right),
$$

where $t$ is the time (s) after sunrise. The day length $(N)$ was calculated as function of latitude using general astronomical formulae. $E_{\max }$ was calculated by multiplying mean daily PAR by $\frac{\pi}{2 N^{\prime}}$ which is equivalent to solving the daily integral of $E\left(\mathrm{PAR}, 0^{+}, t\right)$ for $E_{\max }$. After obtaining $E\left(\mathrm{PAR}, 0^{+}, t\right)$ (that is, the surface irradiance at evenly spread time-points $(t)$ throughout the day) we could reconstruct vertical irradiance profiles for the same time-points from each lake. Using lake specific $K_{\mathrm{d}} \mathrm{PAR}$ and incoming solar irradiance, we generated vertical profiles of $E_{0}(t, z)$ as

$$
E_{0}(t, z)=E\left(\mathrm{PAR}, 0^{+}, t\right) e^{-K_{\mathrm{d}} \mathrm{PAR} \times z},
$$

where $z$ is the depth $(\mathrm{m})$. Reflection at the surface was not considered.

\section{Absorption Measurements}

For particulate absorbance measurements, we filtered $150-750 \mathrm{ml}$ (depending on particle load) of the integrated water sample onto $25 \mathrm{~mm}$ Whatman GF/C glass fiber filters under low vacuum. Samples were kept in liquid nitrogen for 1 week and stored at $-80^{\circ} \mathrm{C}$ prior to analysis. We measured the optical density of the particles $\left(\mathrm{OD}_{\mathrm{p}}(\lambda)\right)$ from 400 to $800 \mathrm{~nm}$ ( $1 \mathrm{~nm}$ resolution) using a slight variation of the quantitative filter technique (QFT) (Mitchell 1990). Notably, our method differed from the QFT in two respects: we used GF/C-filters $(1.2 \mu \mathrm{m}$ pore size) instead of GF/F $(0.7 \mu \mathrm{m})$, and sandwiched the water-saturated sample filter between two glass slides instead of mounting it on a glass slide. The sample was placed in the entrance of an integrating sphere (ISR 2200, Shimadzu scientific instruments, Columbia, Maryland, USA) attached to a double beam Shimadzu UV-2550 spectrophotometer. A water-saturated blank GF/C-filter was placed in the reference port. After the first measurement, we bleached the sample filter with sodium hypochlorite (Tassan and Ferrari 1995). The bleaching oxidizes all pigments on the filter, also pigments that are not directly associated with phytoplankton. Organic and inorganic detritus, including de-pigmented algal remains, is left unbleached. We measured the optical density of this non-algal particulate matter (NAP), $\operatorname{OD}_{\mathrm{NAP}}(\lambda)$, with a watersaturated GF/C-filter in the reference port. Absorption coefficients $\left(\mathrm{m}^{-1}\right)$ of total particulate matter $\left(a_{\mathrm{p}}(\lambda)\right)$, and NAP $\left(a_{\mathrm{NAP}}(\lambda)\right)$, were calculated 
according to Mitchell and others (2002). We used the algorithm of Bricaud and Stramski (1990) to estimate the path-length amplification factor $(\beta)$. Finally, we calculated the absorption coefficient spectra of phytoplankton pigments $\left(a_{\mathrm{ph}}(\lambda) ; \mathrm{m}^{-1}\right)$ as the difference between the total particulate and the NAP absorption coefficient spectra. The mean absorption coefficient for phytoplankton in the PAR region, $\bar{a}_{\mathrm{ph}}(\mathrm{PAR})$, was calculated as the average absorption coefficient between 400 and $700 \mathrm{~nm}$. This was used in the calculation of $\mathrm{PP}_{\mathrm{A}}$.

Samples for CDOM absorbance were stored in Nalgene $60 \mathrm{ml}$ HDPE bottles (Thermo Scientific) at $-20^{\circ} \mathrm{C}$ until analysis. We acknowledge that freezing can lead to reduced specific absorption, especially in high DOC samples (Fellman and others 2008). Thus, absorbance might be slightly underestimated, with high DOC lakes being more affected than low DOC lakes. We filtered $20 \mathrm{ml}$ lake water through a Acrodisc $0.2 \mu \mathrm{m}$ polyethersulfone membrane syringe filter (Pall Life Sciences) and measured the optical density of the filtrate $\left(\operatorname{OD}_{\mathrm{CDOM}}(\lambda)\right)$ in a 50 -mm glass cuvette from 400 to $750 \mathrm{~nm}$ in steps of $1 \mathrm{~nm}$. In the reference cuvette we added Milli-Q water filtered through the same syringe filter. Absorption coefficient spectra of CDOM $\left(a_{\mathrm{CDOM}}(\lambda) ; \mathrm{m}^{-1}\right)$ were calculated according to Mitchell and others (2002).

\section{Water Chemistry}

Concentrations of TP, DOC, and total nitrogen (TN) were measured both at the accredited lab at the Norwegian Institute for Water Research (NIVA) and at the University of Oslo (UiO). TP was measured on an auto-analyzer as phosphate after wet oxidation with peroxodisulfate in both laboratories. We calculated DOC as the difference between total organic carbon (TOC) and particulate organic carbon (POC). TOC was measured by infrared $\mathrm{CO}_{2}$ detection after catalytic high temperature combustion (Shimadzu TOC-VWP analyzer (UiO) or Phoenix 8000 TOC-TC analyzer (NIVA)). POC was measured on an elemental analyzer (Flash EA 1112 NC, Thermo Fisher Scientific, Waltham, Massachusetts, USA) through rapid combustion of a pre-combusted GF/C filter with particulates in pure oxygen, where carbon was detected as $\mathrm{CO}_{2}$ by gas-chromatography. TN was measured by detecting nitrogen monoxide by chemiluminescence using a TNM-1 unit attached to the Shimadzu TOC-VWP analyzer (UiO), or detection of nitrate after wet oxidation with peroxodisulfate in a segmented flow autoanalyzer (NIVA). Differences between laboratories were small for TOC and TN, but slightly higher for TP. Regressions of UiO versus NIVA measurements had the following statistics: TOC: $R^{2}=0.99$, residual standard error $(\mathrm{RSE})=0.25 \mathrm{mg} \mathrm{l}^{-1} ; \mathrm{TN}: R^{2}=0.91, \mathrm{RSE}=81 \mu \mathrm{g} \mathrm{l}^{-1}$; TP: $R^{2}=0.77, \mathrm{RSE}=2.27 \mu \mathrm{g} \mathrm{l^{-1 }}$, with no systematic differences between the labs. We averaged the results from both laboratories for the following analysis.

Total $\mathrm{Fe}$ was measured to assess its potential influence on the absorptive properties of CDOM. We used an inductively coupled plasma mass spectrometer (ICP-MS, PerkinElmer NexION 300, Norwalk, Connecticut, USA) equipped with three quadrupole mass analysers, a cyclonic spray chamber, and a concentric nebulizer. To evaluate analytical precision, three subsamples from each lake were measured and the distribution of $\mathrm{CV}$ values was inspected (1.quartile $0.93 \%$, mean $1.45 \%$, 3.quartile $1.74 \%$ ).

\section{PAM Measurements}

A portable PAM fluorometer (AquaPen-C 100, Photon Systems Instruments, Czech Republic) with blue measuring light (centered at $455 \mathrm{~nm}$ ) was used to measure the response of the quantum yield of photosynthetic electron transport in PSII to increasing irradiance (Ralph and Gademann 2005). Before measurement, an unfiltered water sample was dark-adapted for about $\mathrm{l} \mathrm{h}$ to ensure that all reaction centers were in an "open" state. Immediately after dark-adaptation, we ran a light curve protocol that exposed the sample to six different irradiances $(10,20,50,100,300$, and $500 \mu \mathrm{mol}$ photons $\mathrm{m}^{-2} \mathrm{~s}^{-1}$ ). Each illumination step lasted for $60 \mathrm{~s}$, and during each step the steady state fluorescence $(F)$ was recorded. At the end of every illumination step, a saturating pulse (ca $3000 \mu \mathrm{mol}$ photons $\mathrm{m}^{-2} \mathrm{~s}^{-1}$ ) was given to saturate all reaction centers. During the pulse, the maximum fluorescence in light $\left(F_{\mathrm{m}}^{\prime}\right)$ was measured. Following Kromkamp and Forster (2003), the quantum yield of photosynthetic electron transport in PSII, $\frac{\Delta F}{F^{\prime}}$, could then be calculated as $\frac{F_{\mathrm{m}}^{\prime}-F}{F_{\mathrm{m}}^{\prime}}$. Specifically, this is the potential fraction of photons absorbed by PSII that produces a charge separation; with units of mol electrons (mol photons absorbed $)^{-1}$. Immediately after dark-adaptation (before any exposure to actinic light), the maximum quantum yield of electron transport in PSII is defined as $\frac{F_{\mathrm{v}}}{F_{\mathrm{m}}}=\frac{F_{\mathrm{m}}-F_{0}}{F_{\mathrm{m}}}$. Here, $F_{0}$ is the fluorescence detected by the non-actinic measuring light and $F_{\mathrm{m}}$ the dark-adapted maximum fluorescence.

We modeled the dependency of $\frac{\Delta F}{F_{\mathrm{m}}^{\prime}}$ on irradiance $(E)$ with an exponential decay function: 


$$
\frac{\Delta F}{F_{\mathrm{m}}^{\prime}}(E)=\frac{F_{\mathrm{v}}}{F_{\mathrm{m}}} \times e^{-\frac{E}{E_{\mathrm{k}}}},
$$

where $E_{\mathrm{k}}$ is the "onset of light saturation" parameter $\left(\mu \mathrm{mol}\right.$ photons $\mathrm{m}^{-2} \mathrm{~s}^{-1}$ ). After linearizing the function with a log-transformation, we fitted a linear mixed-effect model to the whole data set with $\frac{F_{\mathrm{v}}}{F_{\mathrm{m}}}$ and $E_{\mathrm{k}}$ as random effects (Pinheiro and Bates 2000). Modeling $\frac{\Delta F}{F_{\mathrm{m}}^{\prime}}$ as a function of $E$ is shown to be more robust than modeling relative ETRs $\left(\mathrm{rETR}=\frac{\Delta F}{F_{\mathrm{m}}^{\prime}} \times E\right)$ because of the dependency between rETR and $E$ (Silsbe and Kromkamp 2012).

\section{Photon Budgets}

Most light absorption in aquatic ecosystems can be attributed to four main components. These are phytoplankton pigments, CDOM (with associated inorganic compounds like Fe), NAP, and the water itself (Kirk 2011). Under this assumption, we can write the total absorption coefficient spectrum of the lake water, $a_{\mathrm{tot}}(\lambda)$, as the sum of the component spectra: $\quad a_{\text {tot }}(\lambda)=a_{\mathrm{ph}}(\lambda)+a_{\mathrm{CDOM}}(\lambda)+a_{\mathrm{NAP}}(\lambda)+$ $a_{\mathrm{w}}(\lambda)$. Values for $a_{\mathrm{w}}(\lambda)$ were taken from Morel and Prieur (1977). Using a representative irradiance spectrum $(E(0, \lambda))$ for incoming sunlight we calculated the fraction of this solar irradiance absorbed by each component $i\left(F_{i}\right)$ as

$$
F_{i}=\int_{400}^{700} w(\lambda) \frac{a_{i}(\lambda)}{\sum a_{i}(\lambda)} \mathrm{d} \lambda,
$$

where $w(\lambda)$ is average spectral distribution of surface irradiance

$$
w(\lambda)=E(0, \lambda)\left[\int_{400}^{700} E(0, \lambda) \mathrm{d} \lambda\right]^{-1} .
$$

$E(0, \lambda)$ used here was obtained from the average of 75 hyper-spectral solar irradiance measurements (sensor: RAMSES-ACC-VIS, TriOS GmbH, Germany); one from the surface of each lake. For simplicity, we assumed an optically deep water column, that is, that $E(0, \lambda)$ was completely absorbed.

\section{Bio-optical Estimation of PP}

Area-specific rates of gross primary productivity $\left(\mathrm{PP}_{\mathrm{A}}\right)$ were estimated using a bio-optical approach (see Kromkamp and Forster 2003, pp. 107-108). Bio-optical PP estimates are believed to correspond most closely to gross PP because they are directly linked to the rate at which electrons flow from water (where $\mathrm{O}_{2}$ is produced) through PSII, to NADPH (Lawrenz and others 2013).

First, we calculated the rate of light absorption by phytoplankton at time $t$ and depth $z$ ( $\mu$ mol photons $\left.\mathrm{m}^{-3} \mathrm{~s}^{-1}\right)$ as

$$
E_{0}(t, z) \times \bar{a}_{\mathrm{ph}}(\mathrm{PAR}),
$$

where $E_{0}(t, z)$ is the scalar irradiance ( $\mu$ mol photons $\left.\mathrm{m}^{-2} \mathrm{~s}^{-1}\right)$ at time-point $t(\mathrm{~s})$ and depth $z(\mathrm{~m})$. $\bar{a}_{\mathrm{ph}}(\mathrm{PAR})$ is the average absorption coefficient for phytoplankton $\left(\mathrm{m}^{-1}\right)$ between 400 and $700 \mathrm{~nm}$. Further, we estimated ETR through PSII $\left(\operatorname{ETR}_{\mathrm{PSII}}(t, z) ; \mu \mathrm{mol} \mathrm{e}^{-} \mathrm{m}^{-3} \mathrm{~s}^{-1}\right)$ by multiplying the rate of light absorption with the quantum yield of electron transport in PSII $\left(\frac{\Delta F}{F_{\mathrm{m}}^{\prime}}\right)$, which depends on irradiance. It was additionally assumed that $50 \%$ of the photons are absorbed by PSII (Gilbert and others 2000):

$\operatorname{ETR}_{\mathrm{PSII}}(t, z)=E_{0}(t, z) \times \bar{a}_{\mathrm{ph}}(\mathrm{PAR}) \times \frac{\Delta F}{F_{\mathrm{m}}^{\prime}}\left(E_{0}(t, z)\right) \times 0.5$.

Finally, we predicted primary productivity $\left(\mathrm{PP}(t, z) ; \mu \mathrm{mol} \mathrm{C} \mathrm{m}^{-3} \mathrm{~s}^{-1}\right)$ by assuming appropriate values for the number of charge separations in PSII per $\mathrm{O}_{2}$ produced $\left(\phi_{e}\right)$ and the number of $\mathrm{CO}_{2}$ fixed per $\mathrm{O}_{2}$ produced (the photosynthetic quotient, $\mathrm{PQ}$ ):

$$
\mathrm{PP}(t, z)=\operatorname{ETR}_{\mathrm{PSII}}(t, z) \times \frac{1}{\phi_{e}} \times \mathrm{PQ} .
$$

Empirical data on $\phi_{e}$, estimated as the ratio of PAM-based ETR to $\mathrm{O}_{2}$ evolution rate, typically range between 4 and 10 (Suggett and others 2010). Although the theoretical minimum value for $\phi_{e}$ is 4 (Emerson 1958), here we applied a value of 5 (Kromkamp and others 2008), which is also the empirical minimum (Ley and Mauzerall 1982). Also, we assumed a photosynthetic quotient of 0.9 $\mathrm{CO}_{2}$ fixed per $\mathrm{O}_{2}$ produced (Williams and Robertson 1991).

We calculated the area-specific PP at all timepoints $t\left(\mathrm{PP}_{\mathrm{A}}(t) ; \mu \mathrm{mol} \mathrm{C} \mathrm{m}{ }^{-2} \mathrm{~s}^{-1}\right)$ by integrating $\operatorname{PP}(t, z)$ from the surface to a depth of $5 \mathrm{~m}$, which is where the integrated water samples were taken from. Also, the phytoplankton showed a reasonably homogenous distribution in this layer as judged from the in vivo fluorescence profiles (data not shown). Finally, we found $\mathrm{PP}_{\mathrm{A}}\left(\mathrm{mg} \mathrm{C} \mathrm{m}{ }^{-2}\right.$ day ${ }^{-1}$ ) by integrating $\mathrm{PP}_{\mathrm{A}}(t)$ over the day, and converting from $\mu \mathrm{mol} \mathrm{C}$ to $\mathrm{mg} \mathrm{C}$.

We calculated the effects of TP, CDOM, and DOC concentration on the $\mathrm{PP}_{\mathrm{A}}$ estimates using multiple regressions. To correct for the latitude-dependent variation in insolation, we used $\mathrm{PP}_{\mathrm{A}} / \mathrm{PAR}$ (with PAR being the daily average incoming solar 
irradiance) as a response variable instead of $\mathrm{PP}_{\mathrm{A}}$ directly.

\section{RESUlTS \\ Water Chemistry}

Both DOC and TP spanned wide gradients. DOC concentration ranged from 0.25 to $12.3 \mathrm{mg} \mathrm{l}^{-1}$ and TP from 0.5 to $27.5 \mu \mathrm{g} \mathrm{l}^{-1}$ (Table 1). The variables were correlated $\left(P<0.001, R^{2}=0.32\right.$ with both variables log-transformed), but exhibited considerable variability, indicating that reasonably orthogonal gradients were captured (Figure 1A). TN and TP showed a positive relationship $\left(P<0.001, R^{2}=0.22\right.$ with both variables logtransformed). In all lakes, TN:TP were well above Redfield proportions (7.2:1 on weight basis; Figure 1B; Table 1), which is often taken as an indication of the transition from $\mathrm{N}$ to $\mathrm{P}$ limitation. Fe was strongly correlated with DOC (Figure 1C; $P<0.001, R^{2}=0.65$ with Fe log-transformed).

\section{CDOM, DOC Concentration, and Light Absorption}

CDOM, expressed as the absorption coefficient of the dissolved fraction at $400 \mathrm{~nm}\left(a_{\mathrm{CDOM}}(400)\right)$, was strongly related to DOC concentration (Figure 2A; Table 2). Modeling CDOM as a function of $\mathrm{Fe}$ yielded a similar positive relationship (Figure 2B). Actually, the $R^{2}$ values for the two simple linear regressions were exactly similar (Table 2 ). Including both $\mathrm{Fe}$ and DOC as predictors of CDOM increased $R^{2}$ to 0.85 (Table 2 ), suggesting an additive chromophoric effect of Fe on DOC.

DOC and Fe were both positively related to $K_{\mathrm{d}} \mathrm{PAR}$ (Figure 2C, D). Together with TP, DOC explained $67 \%$ of the variation in this variable (Table 2). Substituting DOC with Fe in the regression model, the explained variance increased to $82 \%$ (Table 2). This indicates an important contribution of iron to the total in situ attenuation of PAR.

\section{Fractional PAR Absorbance}

Total absorption spectra (the sum of the four component spectra) and contributions from the four main absorbing components differed strongly between lakes with different levels of DOC and TP. This is exemplified with a clear oligotrophic, a eutrophic, and a humic lake (Figure 3). Notably, CDOM was by far the dominant absorber of photosynthetic active irradiance in all lakes (Figure 4). The component captured on average $57.3 \%$ of the available photons, with fractions ranging from 36.9 to $76.2 \%$. Absorption by CDOM was most important in the blue part of the spectrum (400-550 nm), where it captured the vast majority of photons (Figure 5). The mean fraction of irradiance absorbed by phytoplankton pigments was $6.6 \%$, with a range from 2.2 to $28.2 \%$. The proportion was positively related to $\mathrm{TP}$, reflecting phytoplankton biomass, and negatively to DOC, reflecting the strong shading imposed by CDOM (Table 2). Across the PAR spectrum, the relative contribution of phytoplankton to the total absorption coefficient peaked at $675 \mathrm{~nm}$ (Figure 5), where chlorophyll $a$ has its red absorption peak in vivo. The blue absorption peak disappears almost completely when looking at the absorption coefficient relative to the other components because CDOM absorbs so strongly in this part of the spectrum. The mean fraction absorbed by NAP was $7.2 \%$ (range 1.6$20.7 \%$ ), and the water itself $29.5 \%$ (range $15.7-$ $48.1 \%)$.

\section{PP and the Effects of CDOM, DOC, and $\mathrm{TP}$}

The bio-optical estimates of $\mathrm{PP}_{\mathrm{A}}$ spanned from 48 to $993 \mathrm{mg} \mathrm{C} \mathrm{m}^{-2}$ day $^{-1}$ with a median of $286 \mathrm{mg} \mathrm{C} \mathrm{m}^{-2}$ day $^{-1}$ (Figure 6). Both CDOM and $\mathrm{TP}$ were highly significant predictors for $\mathrm{PP}_{\mathrm{A}}$ in a multiple regression (Table 3, model A). Notably, the variables came out with opposite signs and similar effect sizes. We found a positive effect of TP on $\mathrm{PP}_{\mathrm{A}}$ which, given the generally high TN:TP ratios, should be indicative of P-limitation. The

Table 1. Summary Statistics Describing the Distributions of Important Water Chemical Variables

\begin{tabular}{llllll}
\hline Quantity (unit) & Min & First quantile & Median & Third quantile & Max \\
\hline DOC $\left(\mathrm{mg} \mathrm{l}^{-1}\right)$ & 0.25 & 3.45 & 5.9 & 7.4 & 12.3 \\
TP $\left(\mu \mathrm{g} \mathrm{l}^{-1}\right)$ & 0.5 & 2.9 & 4.55 & 7.3 & 27.45 \\
Fe $\left(\mu \mathrm{g} \mathrm{l}^{-1}\right)$ & 7.2 & 52.5 & 127.2 & 206.1 & 866 \\
TN (mg l & 0.087 & 0.23 & 0.3 & 1.44 & 1.53 \\
DOC:TP (mg:mg) & 148.9 & 749 & 1227 & 115.6 & 5415 \\
TN:TP (mg:mg) & 17.4 & 46.4 & 66.7 & 30.2 & 570.6 \\
Fe:DOC ( $\mu \mathrm{g}: \mathrm{mg})$ & 6 & 13.9 & 23.6 & 519 \\
\hline
\end{tabular}



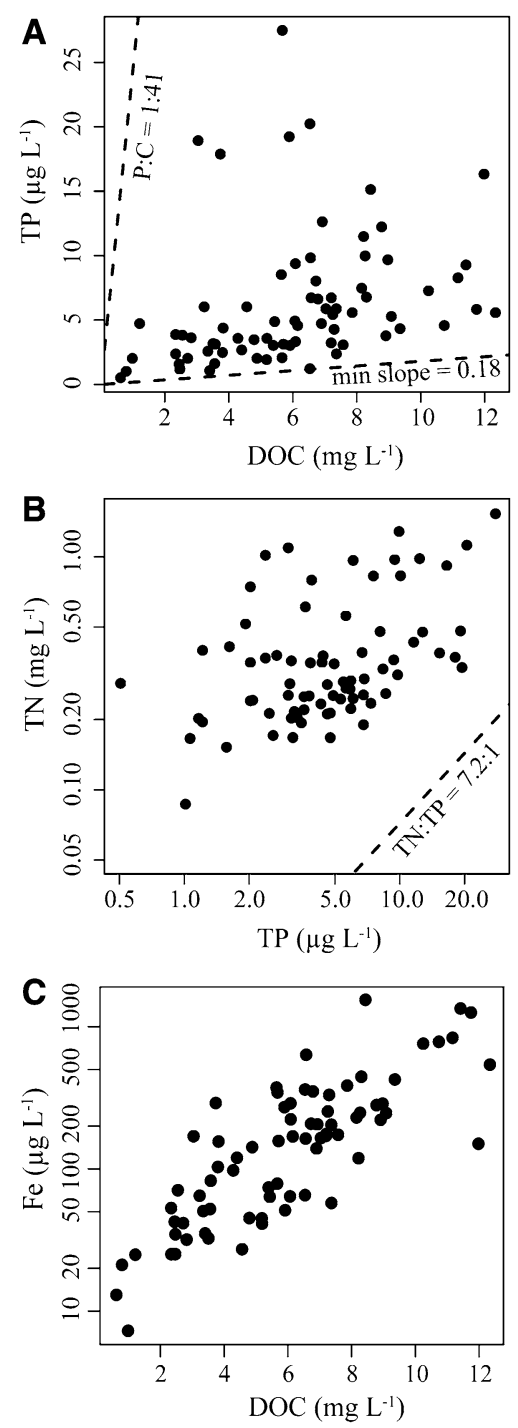

Figure 1. A The relationship between TP $\left(\mu \mathrm{g} \mathrm{l}^{-1}\right)$ and DOC $\left(\mathrm{mg} \mathrm{l}^{-1}\right)$. The upper dotted line indicates the Redfield ratio of $\mathrm{P}: \mathrm{C}$ (1:41 on weight basis). All lakes had P:C ratios substantially below this value, indicating high input of $\mathrm{C}$ from allochthonous sources. The lower dotted line has a slope equal to the lowest $\mathrm{P}: \mathrm{C}$ ratio observed among the lakes (0.18 $\mu \mathrm{g}$ TP:mg DOC; see "Discussion" section). B The relationship between $\mathrm{TN}\left(\mathrm{mg} \mathrm{l}^{-1}\right)$ and TP $\left(\mu \mathrm{g} \mathrm{l}^{-1}\right)$. The dotted line represents the Redfield ratio of $\mathrm{N}: \mathrm{P}$ (7.2:1 on weigh basis). All lakes were above this ratio, indicating P-limitation. C The relationship between Fe $\left(\mu \mathrm{g} \mathrm{l}^{-1}\right)$ and DOC $\left(\mathrm{mg} \mathrm{l}^{-1}\right)$. Notice both axes log-transformed in $\mathbf{B}$ and $y$-axis log-transformed in $\mathbf{C}$.

coefficient for $\log (\mathrm{TP})$ in the regression model for $\log \left(\mathrm{PP}_{\mathrm{A}} / \mathrm{PAR}\right)$ (0.42; see Table 3$)$ can be interpreted as follows. A doubling of TP while keeping CDOM constant would give a $34 \%$ increase in $\mathrm{PP}_{\mathrm{A}} / \mathrm{PAR}$ $\left(2^{0.42}-1=0.34\right)$. The significant negative regression coefficient for $\log (\mathrm{CDOM})(-0.55$; see Table 3$)$ indicates that a doubling of CDOM, while keeping
TP constant, should lead to a $32 \%$ decrease in $\mathrm{PP}_{\mathrm{A}} /$ PAR $\left(1-\left(2^{-0.55}\right)=0.32\right) \cdot R^{2}$ for the model was 0.32 . We also ran the regression using DOC concentration and TP as predictors. In general, this yielded very similar results (Table 3 , model B), albeit slightly higher explained variance $\left(R^{2}=0.4\right.$ vs. $R^{2}=0.32$ ). Following the same rationale for interpreting the model coefficients, a doubling of TP would lead to a $39 \%$ increase in $\mathrm{PP}_{\mathrm{A}} / \mathrm{PAR}$ according to this model, whereas a doubling of DOC would cause a $38 \%$ decrease. Interestingly, including Fe as a third predictor in the regressions did not significantly increase the explained variation in $\mathrm{PP}_{\mathrm{A}} / \mathrm{PAR}$, despite its chromophoric effects on CDOM.

\section{Discussion}

Both the fraction of irradiance absorbed by the different components (Figure 4) and the spectral decomposition of total absorbance spectra (Figure 5) revealed that in these boreal lakes, phytoplankton pigments are of relatively minor importance for the fate of photons. This can be attributed to low phytoplankton biomass per se, but even more to absorption by other chromophoric compounds, notably CDOM (compare Jones 1992). In the vast majority of the lakes, CDOM captured the largest fraction of photons in the PAR region.

Our results clearly illustrate the contrasting effects of nutrients (TP) and CDOM or DOC on $\mathrm{PP}_{\mathrm{A}}$ (Table 3). Even though $\mathrm{PP}_{\mathrm{A}}$ is a snapshot measurement based on the optical and biological conditions at the time of sampling, it also accounts for effects of nutrients. The positive effect of TP reflects the generally P-limited state of these lakes (Figure 1B; Table 1). Specifically, TP influences the $\mathrm{PP}_{\mathrm{A}}$ estimates by affecting two terms in the bio-optical model. First, phytoplankton biomass increases with TP. The phytoplankton absorption coefficient roughly follows the biomass (ignoring package effects), resulting in a higher rate of light absorption, higher ETR, and higher PP. Second, the quantum yield of PSII likely also reflects nutrient conditions and is reduced under nutrient limitation (Kolber and others 1988); especially nutrient starvation (Parkhill and others 2001).

The negative CDOM or DOC effect is most likely explained by shading (Carpenter and others 1998; Karlsson and others 2009). High CDOM or DOC results in reduced light availability (the $E_{0}$ term in the bio-optical model); also supported by the positive relationship between DOC and the two attenuation coefficients $K_{\mathrm{d}} \mathrm{PAR}$ and $a_{\mathrm{CDOM}}(400)$ (Figure 2A, C). Arguably, the depth of the euphotic 

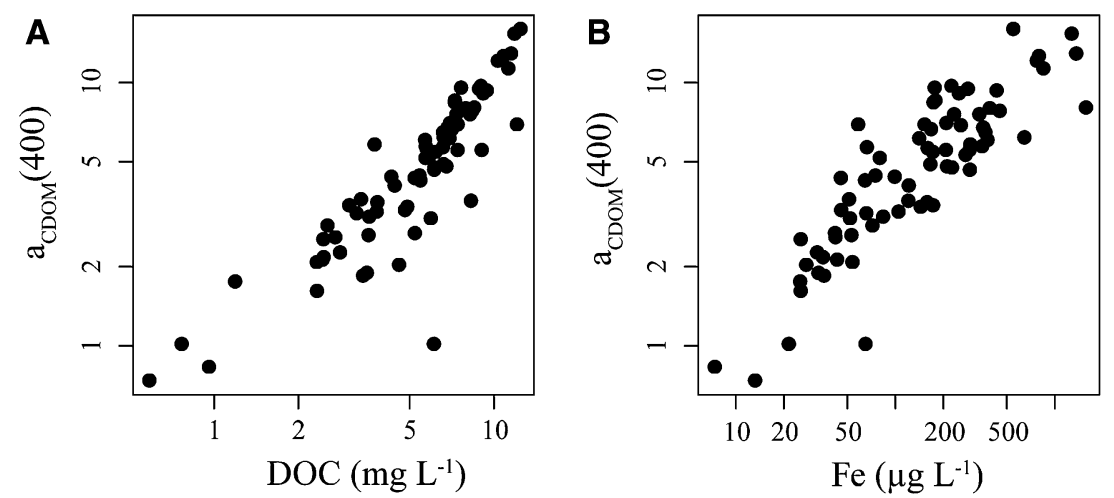

Figure 2. A The relationship between CDOM $\left(a_{\mathrm{CDOM}}(400)\right.$; $\left.\mathrm{m}^{-1}\right)$ and $\operatorname{DOC}\left(\mathrm{mg} \mathrm{l}^{-1}\right)$, B CDOM and Fe $\left(\mu \mathrm{g} \mathrm{l}^{-1}\right)$, C $K_{\mathrm{d}} \mathrm{PAR}\left(\mathrm{m}^{-1}\right)$ and DOC, and $\mathbf{D} K_{\mathrm{d}} \mathrm{PAR}$ and Fe. All axes are log-transformed.
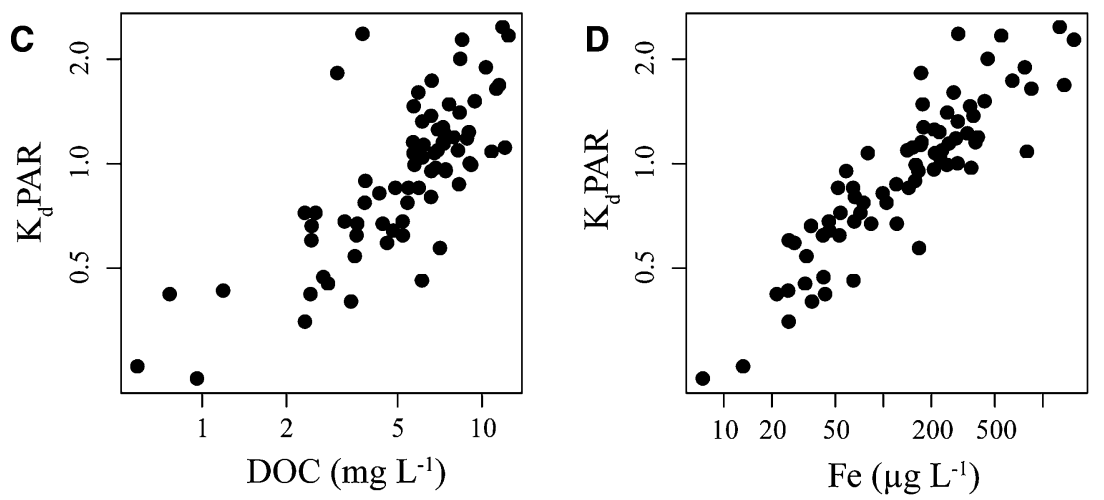

Table 2. Regression Coefficients for Regressions Predicting $a_{\mathrm{CDOM}}(400), K_{\mathrm{d}} \mathrm{PAR}$, and Percentage of PAR Absorbed by Pigments

\begin{tabular}{llll}
\hline Response & Predictors & Estimates (SE, signif. level) & $R^{2}$ \\
\hline A) $\log \left(a_{\mathrm{CDOM}}(400)\right)$ & $\log (\mathrm{DOC})$ & $0.95\left(0.062^{* *}\right)$ & 0.76 \\
B) $\log \left(a_{\mathrm{CDOM}}(400)\right)$ & $\log (\mathrm{Fe})$ & $0.51\left(0.034^{* *}\right)$ & 0.76 \\
C) $\log \left(a_{\mathrm{CDOM}}(400)\right)$ & $\log (\mathrm{DOC})+\log (\mathrm{Fe})$ & $0.54\left(0.082^{* *}\right), 0.28\left(0.045^{* *}\right)$ & 0.85 \\
D) $\log \left(K_{\mathrm{d}} \mathrm{PAR}\right)$ & $\log (\mathrm{TP})+\log (\mathrm{DOC})$ & $0.24\left(0.053^{* *}\right), 0.45\left(0.068^{* *}\right)$ & 0.67 \\
E) $\log \left(K_{\mathrm{d}} \mathrm{PAR}\right)$ & $\log (\mathrm{TP})+\log (\mathrm{Fe})$ & $0.096\left(0.044^{*}\right), 0.356\left(0.013^{* *}\right)$ & 0.82 \\
F) $\log ($ perc.pigm $)$ & $\log (\mathrm{TP})+\log (\mathrm{DOC})$ & $0.38\left(0.058^{* *}\right),-0.40\left(0.066^{* *}\right)$ & 0.43
\end{tabular}

$a_{\mathrm{CDOM}}(400)$ and $K_{\mathrm{d}} \mathrm{PAR}$ have units $\mathrm{m}^{-1}, \mathrm{TP}$ and $\mathrm{Fe} \mu \mathrm{g} \mathrm{l}^{-1}$, and DOC $\mathrm{mg} \mathrm{l}^{-1}$. Perc.pigm is the fraction of irradiance absorbed by phytoplankton pigments. Signif. codes: $* * P<0.0001, * P<0.05$.

zone will decrease with increased CDOM given a constant phytoplankton concentration. This lowers the vertical extent of positive primary production and necessarily also its depth integral, the areaspecific productivity. Because DOC constitutes a major fraction of CDOM in these lakes (Figure 2; Table 2), as for boreal lakes in general (Tranvik 1990; Pace and Cole 2002), DOC displays a similar negative effect.

The CDOM quantity $\left(a_{\mathrm{CDOM}}(400)\right)$ incorporates the absorption by DOC, but also the absorption by inorganic constituents such as iron (Vähätalo 2009). In fact, increased iron concentrations have been proposed as an important factor in the browning of boreal lakes (Sarkkola and others
2013). The scatter in the plot of $a_{\mathrm{CDOM}}(400)$ versus DOC (Figure 2A) indicates a significant variation in specific DOC absorption among lakes. Including both DOC and Fe as predictors of $a_{C D O M}(400)$, we observed a higher $R^{2}$ than each of the predictors in separate simple linear regressions (Table 2). This indicates that some of the variation in specific DOC absorption is explained by $\mathrm{Fe}$, as recently found for Swedish and Canadian lakes (Weyhenmeyer and others 2014). Because DOC and Fe are so closely correlated (Figure 1C) it is, however, difficult to estimate the relative contribution of each of them to the CDOM component. Importantly, DOC and Fe concentrations are not independent because ionic Fe has low solubility under oxic conditions 

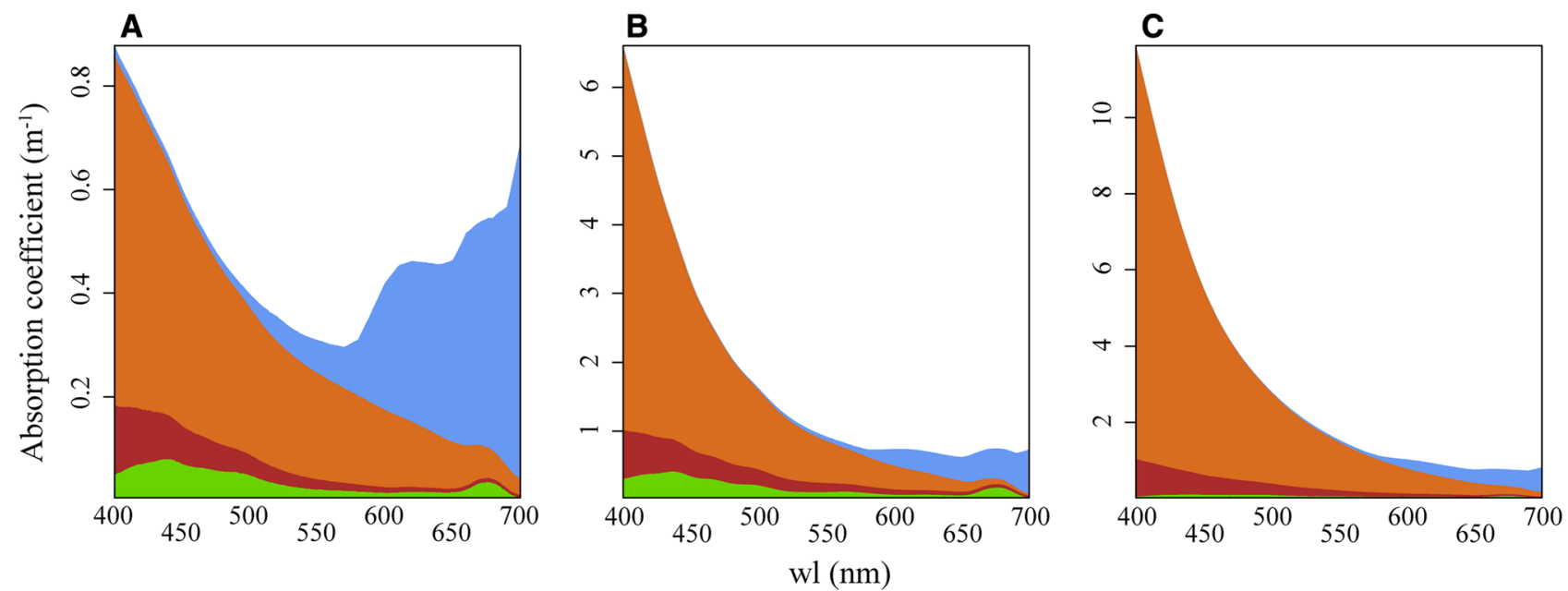

Figure 3. Total absorption spectra for three lakes with different levels of DOC, TP, and Secchi disc depth (SD). The component spectra are stacked upon each other; each colored area represents the absorption spectrum of one of the four components (phytoplankton: green, NAP: dark brown, CDOM: light brown, and water: blue). Note that values on the $y$-axis differ. A Lake Jølstravannet (oligotrophic; SD $10 \mathrm{~m}, \mathrm{TP}<1 \mu \mathrm{g} \mathrm{l}{ }^{-1}$, DOC $0.57 \mathrm{mg} \mathrm{l}^{-1}$ ), B Lake Bergsvannet (eutrophic; SD $1.05 \mathrm{~m}$, TP $17.85 \mathrm{~g} \mathrm{l}^{-1}$, DOC $3.7 \mathrm{mg} \mathrm{l}^{-1}$ ), C Lake Rokosjøen (humic and mesotrophic; SD $1.8 \mathrm{~m}, \mathrm{TP} 8.25 \mu \mathrm{g} \mathrm{l}{ }^{-1}$, DOC $\left.11.12 \mathrm{mg} \mathrm{l}^{-1}\right)$.

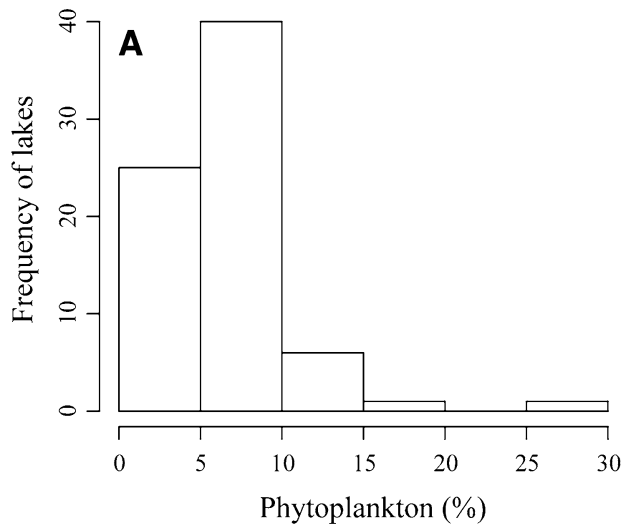

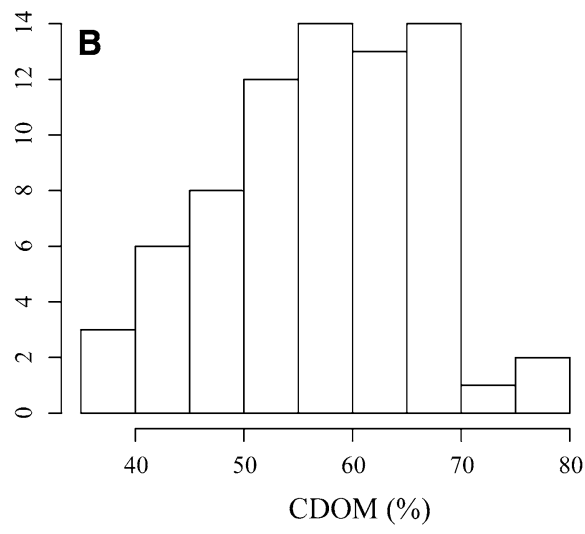

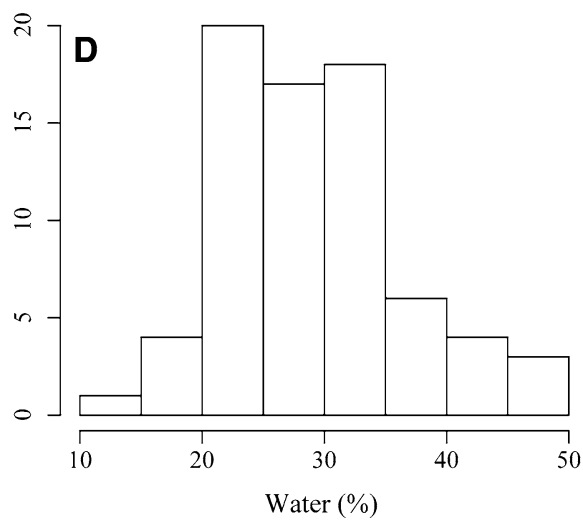

Figure 4. Histograms showing the fraction of photosynthetic active irradiance absorbed by $\mathbf{A}$ phytoplankton pigments (mean 6.6\%), B CDOM (mean $56.3 \%$ ), C NAP (mean $7.2 \%$ ), and $\mathbf{D}$ the water itself (mean 29.5\%) in the 75 lakes. Values were calculated on the basis of component absorption spectra and a spectrum of incoming solar irradiance.

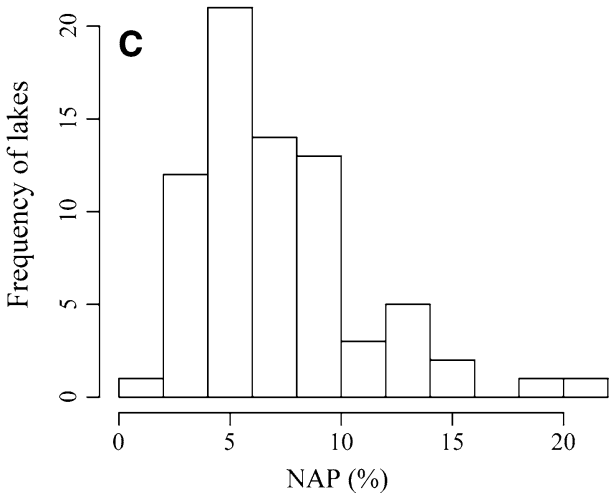

unless being complexed by DOC (Maranger and Pullin 2003). This implies that high Fe concentrations must be associated with high DOC concentrations in lakes, although not necessarily vice versa. The fact that we found no additive negative effect of $\mathrm{Fe}$ on $\mathrm{PP}_{\mathrm{A}}$ was surprising, considering the effect of Fe on light absorption. Because CDOM and DOC are so closely correlated with Fe, the negative 


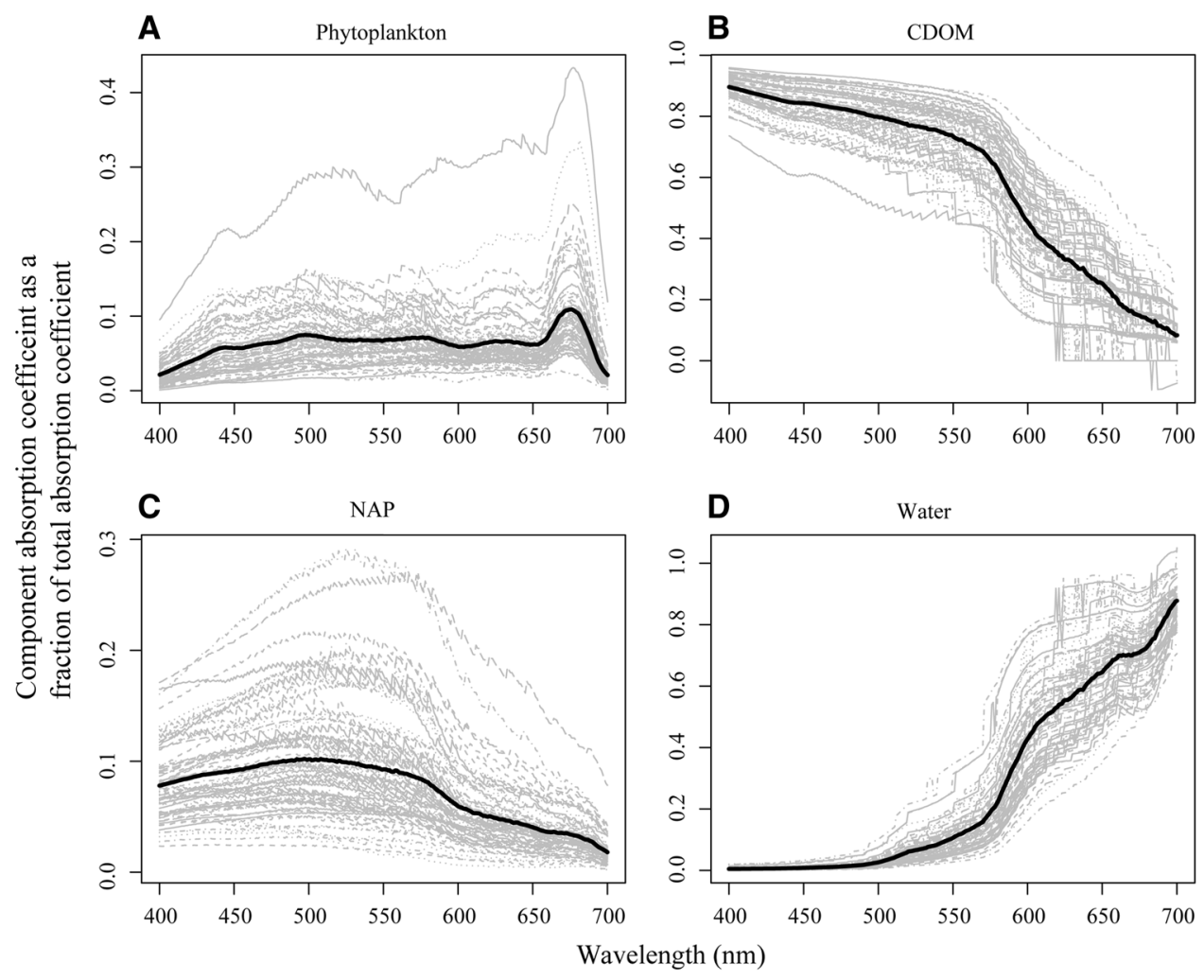

Figure 5. The relative contribution of $\mathbf{A}$ phytoplankton pigments, B CDOM, C NAP, and $\mathbf{D}$ water to the total absorption coefficient across the PAR spectrum. The $y$-axis is the fraction of the total absorption coefficient constituted by each component, calculated as $\frac{a_{i}(\lambda)}{a_{\mathrm{tot}}(\lambda)^{\prime}}$, where $a_{i}(\lambda)$ is the absorption coefficient of component $i$ at wavelength $\lambda$, and $a_{\text {tot }}(\lambda)=a_{\text {phyto }}(\lambda)+a_{\mathrm{CDOM}}(\lambda)+a_{\mathrm{NAP}}(\lambda)+a_{\mathrm{w}}(\lambda)$. The solid black lines represent the average across all lakes. Gray lines are individual lakes.

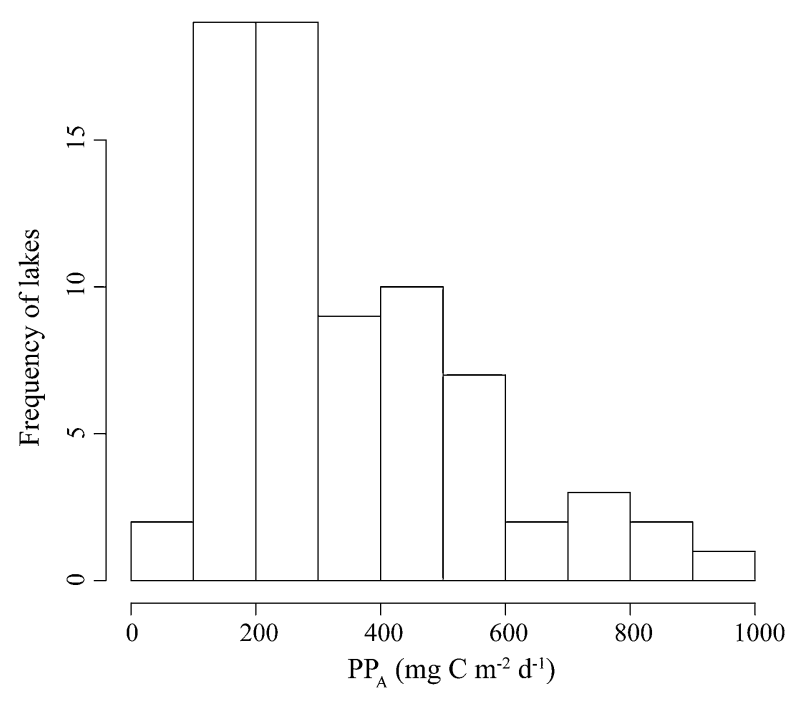

Figure 6. Frequency distribution showing the bio-optical estimates of $\mathrm{PP}_{\mathrm{A}}\left(\mathrm{mg} \mathrm{C} \mathrm{m}{ }^{-2}\right.$ day $\left.^{-1}\right)$ from the 75 lakes. The estimates are maximum gross values calculated over the vertical layer from 0 to $5 \mathrm{~m}$. effect of CDOM or DOC possibly accounts for most of the Fe effect so that little residual variation can be explained by including Fe. Furthermore, Fe may stimulate PP in low DOC-lakes in the same region (Vrede and Tranvik 2006). Whether this may cancel out the light-absorptive effects remains unsettled, but is worth pursuing.

The absolute values of $\mathrm{PP}_{\mathrm{A}}\left(\mathrm{mg} \mathrm{C} \mathrm{m}^{-2}\right.$ day $\left.^{-1}\right)$ should be interpreted with some caution due to the assumptions about a constant $\phi_{e}$ and PQ underlying the conversion from ETR to carbon fixation (Suggett and others 2010). These parameters might vary with environmental conditions and phytoplankton taxonomic composition (Lawrenz and others 2013), but the values chosen here $\left(\phi_{e}=5\right.$, $P Q=0.9)$ are close to the maximum observed "efficiencies" (Ley and Mauzerall 1982; Williams and Robertson 1991). Hence, they should provide a reasonable upper bound of productivity given the nutrient and light conditions at the time of sampling. Our estimates match empirical estimates of 
Table 3. Regression Coefficients for Regressions Predicting $\mathrm{PP}_{\mathrm{A}} / \mathrm{PAR}$

\begin{tabular}{llll}
\hline Response & Predictors & Estimates (SE, signif. level) & $R^{2}$ \\
\hline A) $\log \left(\mathrm{PP}_{\mathrm{A}} / \mathrm{PAR}\right)$ & $\log (\mathrm{CDOM})+\log (\mathrm{TP})$ & $-0.55\left(0.107^{* *}\right), 0.42\left(0.089^{* *}\right)$ & 0.32 \\
B) $\log \left(\mathrm{PP}_{\mathrm{A}} / \mathrm{PAR}\right)$ & $\log (\mathrm{DOC})+\log (\mathrm{TP})$ & $-0.7\left(0.109^{* *}\right), 0.48\left(0.084^{* *}\right)$ & 0.40
\end{tabular}

Note that $P P_{A} / P A R$ (where $P A R$ is the daily average solar irradiance hitting the lake) was used as a response variable instead of $P P_{A}$ directly. This was done to correct the $P P_{A}$ estimates for the difference in incoming solar irradiance, which depends on latitude. CDOM is defined as $a_{\mathrm{CDOM}}(400)$, with units $m^{-1}$.

Signif. codes: ${ }^{* * P}<0.0001$.

gross $\mathrm{PP}_{\mathrm{A}}$ from boreal lakes (Dokulil and Kaiblinger 2009), and uncertainty in $\phi_{e}$ and PQ should not introduce systematic errors across the gradients that we study (that is, DOC and TP). Moreover, Kromkamp and others (2008) found a linear relationship between rates of photosynthesis (mmol C (mg chl $\left.a)^{-1} \mathrm{~h}^{-1}\right)$ estimated by a corresponding bio-optical method and rates of photosynthesis measured by the ${ }^{14} \mathrm{C}$-method, with the bio-optical rate estimates being systematically slightly higher.

\section{DOC-Mediated Climate Change Effects on PP}

Increased catchment vegetation cover, driven by upward trends in temperature and precipitation, leads to higher carbon export from catchments to lakes. Consequently, the concentration of DOC in most boreal lakes is predicted to increase under a moderate climate change scenario (Larsen and others 201la). Being highly colored, this allochthonous DOC would lead to higher levels of CDOM, possibly also in conjunction with iron (Kritzberg and Ekström 2012). Increased CDOM would lead to higher light attenuation, and likely also lower $\mathrm{PP}_{\mathrm{A}}$.

Larsen and others (2011c) predicted TOC concentrations in 22,000 boreal lakes from catchment data under current conditions, as well as projecting the model for an IPCC B2 climate scenario (http:// www.ipcc.ch/pdf/special-reports/spm/sres-en.pdf). Using the raw data from this study we computed the distribution of relative increases in DOC, assuming $\mathrm{DOC}=0.95 \times$ TOC. Applying the regression model (Table 3, model B), the predicted median DOC increase $(27 \%)$ would translate into a $15 \%$ reduction of $\mathrm{PP}_{\mathrm{A}}\left(1-\left(1.27^{-0.7}\right)=0.15\right)$ when keeping $\mathrm{TP}$ concentration constant. The third quartile of the distribution was $86 \%$. This suggests at least a $35 \%$ $\left(1-\left(1.86^{-0.7}\right)=0.35\right)$ decrease in $\mathrm{PP}_{\mathrm{A}}$ in the $25 \%$ of the lakes experiencing the highest relative DOC increase.

Note that a few important mechanisms might counteract the negative effect of DOC on $\mathrm{PP}_{\mathrm{A}}$. First, export of DOC and TP is correlated in boreal lakes (Dillon and Molot 1997); a trend also observed in our lakes (Figure 1). P bound to dissolved organic matter might stimulate PP if it becomes bio-available (Vähätalo and others 2003). As a rough estimate of the input of $\mathrm{P}$ associated with DOC, we calculated the minimum ratio of TP:DOC ( $\mu \mathrm{g}: \mathrm{mg}$ ) from the lake data. The solid line in Figure 1 has a slope equal to this ratio (0.18). Specifically, this indicates that TP would increase with approxi-

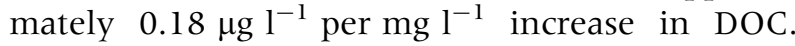
Because the effect sizes of DOC and TP were very similar in the regression for $\mathrm{PP}_{\mathrm{A}}$ (doubling of DOC gave $38 \%$ reduction in $\mathrm{PP}_{\mathrm{A}}$, doubling of $\mathrm{TP}$ gave $39 \%$ increase in $\mathrm{PP}_{\mathrm{A}}$ ), the net effect of an increase in DOC would still be reduced $\mathrm{PP}_{\mathrm{A}}$. However, the magnitude of this effect would depend on the absolute increase in DOC and the background concentration of TP. For example, if DOC doubles from 2 to $4 \mathrm{mg} \mathrm{l}^{-1}$, the negative effect on $\mathrm{PP}_{\mathrm{A}}$ would be stronger in a lake with $10 \mu \mathrm{g} \mathrm{TP} \mathrm{l}^{-1}$ than a lake with $2 \mu \mathrm{g} \mathrm{TP} \mathrm{l}^{-1}$. This is because the relative increase in TP would be higher in the latter. If DOC doubles from, for example 8-16 $\mathrm{mg} \mathrm{l}^{-1}$ (a higher absolute increase), the negative effect on $\mathrm{PP}_{\mathrm{A}}$ would be less due to the counteracting effects of TP.

It has been suggested that volumetric rates of PP are enhanced by increased $\mathrm{CO}_{2}$ in boreal, nutrientpoor lakes (Jansson and others 2012). Because $p \mathrm{CO}_{2}$ generally is tightly linked with DOC (Jonsson and others 2003; Larsen and others 2011b), this could imply an indirect positive effect of DOC on PP. Note, however, that the Jansson and others study measured an increase in volumetric PP under light-saturated conditions. This is a very different quantity than the area-specific PP because it does not account for the attenuation of light with depth.

To conclude, our study shows negative effects of CDOM and DOC concentration on $\mathrm{PP}_{\mathrm{A}}$, likely explained by shading which leads to reduced euphotic depth and faster attenuation of blue light in the water column. In a future scenario of increased DOC concentrations, this might impose negative effects on $\mathrm{PP}_{\mathrm{A}}$ in boreal lakes with consequences for higher trophic levels. We believe that 
the wide gradients in DOC and TP in our study further strengthen this conclusion.

\section{ACKNOWLEDGMENTS}

We thank Johnny Håll, Marcia Kyle, Anna Winter, Robert Ptacnik, Serena Rasconi, Markus Lindholm, Per J. Færøvig, Birger Skjelbred, and Maren Striebel for assistance in the field and for planning of study design. We are also greatly thankful to Cathrine Brecke Gundersen for ICP-MS analysis and to Berit Kaasa for chemical analysis. STRÅNG data used here are from the Swedish Meteorological and Hydrological Institute (SMHI), and were produced with support from the Swedish Radiation Protection Authority and the Swedish Environmental Agency. The study was funded by the Department of Biosciences, University Oslo, and two projects funded by the Research Council of Norway: COMSAT, grant $196336 / \mathrm{S} 30$ to T. Andersen and ECCO, grant 224779 to D.O. Hessen.

\section{OPEN ACCESS}

This article is distributed under the terms of the Creative Commons Attribution License which permits any use, distribution, and reproduction in any medium, provided the original author(s) and the source are credited.

\section{REFERENCES}

Bricaud A, Morel A, Prieur L. 1981. Absorption by dissolved organic matter of the sea (yellow substance) in the UV and visible domains. Limnol Oceanogr 26:43-53.

Bricaud A, Stramski D. 1990. Spectral absorption coefficients of living phytoplankton and nonalgal biogenous matter: a comparison between the Peru upwelling area and the Sargasso Sea. Limnol Oceanogr 35:562-82.

Carpenter S, Cole J, Mitchell J, Pace M. 1998. Impact of dissolved organic carbon, phosphorus, and grazing on phytoplankton biomass and production in experimental lakes. Limnol Oceanogr 43:73-80.

Cole JJ, Pace ML, Carpenter SR, Kitchell JF. 2000. Persistence of net heterotrophy in lakes during nutrient addition and food web manipulations. Limnol Oceanogr 45:1718-30.

Dillon PJ, Molot L. 1997. Effect of landscape form on export of dissolved organic carbon, iron, and phosphorus from forested stream catchments. Water Resour Res 33:2591-600.

Dokulil MT, Kaiblinger C. 2009. Phytoplankton productivity. In: Likens GE, Ed. Encyclopedia of inland waters. London: Elsevier Inc. p 210-18.

Emerson R. 1958. The quantum yield of photosynthesis. Annu Rev Plant Physiol 9:1-24.

Evans CD, Chapman PJ, Clark JM, Monteith DT, Cresser MS. 2006. Alternative explanations for rising dissolved organic carbon export from organic soils. Glob Change Biol 12:2044-53.

Fellman JB, D'Amore DV, Hood E. 2008. An evaluation of freezing as a preservation technique for analyzing dissolved organic C, $\mathrm{N}$ and $\mathrm{P}$ in surface water samples. Sci Total Environ 392:305-12.

Genty B, Briantais J-M, Baker NR. 1989. The relationship between the quantum yield of photosynthetic electron transport and quenching of chlorophyll fluorescence. Biochim Biophys Acta 990:87-92.

Gilbert M, Domin A, Becker A, Wilhelm C. 2000. Estimation of primary productivity by chlorophyll $a$ in vivo fluorescence in freshwater phytoplankton. Photosynthetica 1:111-26.

Henriksen A, Skjelvåle BL, Mannio J, Wilander A, Curtis C, Jensen JP, Fjeld E, Moiseenko T, Harriman R. 1998. Northern European lake survey, 1995. Ambio 27:80-91.

Jansson M, Karlsson J, Jonsson A. 2012. Carbon dioxide supersaturation promotes primary production in lakes. Ecol Lett 15:527-32.

Jones RI. 1992. The influence of humic substances on lacustrine planktonic food chains. Hydrobiologia 229:73-91.

Jonsson A, Karlsson J, Jansson M. 2003. Sources of carbon dioxide supersaturation in clearwater and humic lakes in Northern Sweden. Ecosystems 6:224-35.

Karlsson J, Byström P, Ask J, Ask P, Persson L, Jansson M. 2009. Light limitation of nutrient-poor lake ecosystems. Nature 460:506-9.

Kirk JTO. 1976. Yellow substance (Gelbstoff) and its contribution to the attenuation of photosynthetically active radiation in some inland and coastal south-eastern Australian waters. Aust J Mar Freshw Res 27:61-71.

Kirk JTO. 2011. Light and photosynthesis in aquatic ecosystems. 3rd edn. Cambridge: Cambridge University Press.

Kolber Z, Zehr J, Falkowski P. 1988. Effects of growth irradiance and nitrogen limitation on photosynthetic energy conversion in photosystem II. Plant Physiol 88:923-9.

Kritzberg ES, Ekström SM. 2012. Increasing iron concentrations in surface waters: a factor behind brownification? Biogeosciences 9:1465-78.

Kromkamp JC, Dijkman NA, Peene J, Simis SGH, Gons HJ. 2008. Estimating phytoplankton primary production in Lake IJsselmeer (The Netherlands) using variable fluorescence (PAMFRRF) and C-uptake techniques. Eur J Phycol 43:327-44.

Kromkamp J, Forster R. 2003. The use of variable fluorescence measurements in aquatic ecosystems: differences between multiple and single turnover measuring protocols and suggested terminology. Eur J Phycol 38:103-12.

Larsen S, Andersen T, Hessen DO. 201 la. Climate change predicted to cause severe increase of organic carbon in lakes. Glob Change Biol 17:1186-92.

Larsen S, Andersen T, Hessen DO. $2011 \mathrm{~b}$. The $\mathrm{pCO}_{2}$ in boreal lakes: organic carbon as a universal predictor? Glob Biogeochem Cycles 25:1-8.

Larsen S, Andersen T, Hessen DO. 2011c. Predicting organic carbon in lakes from climate drivers and catchment properties. Glob Biogeochem Cycles 25:1-10.

Lawrenz E, Silsbe G, Capuzzo E, Ylöstalo P, Forster RM, Simis SGH, Prášil O, Kromkamp JC, Hickman AE, Moore CM, Forget M-H, Geider RJ, Suggett DJ. 2013. Predicting the electron requirement for carbon fixation in seas and oceans. PLoS One 8:e58137. doi:10.1371/journal.pone.0058137.

Leenheer JA, Croue J-P. 2003. Characterizing dissolved aquatic organic matter. Environ Sci Technol 31:18A-26.

Ley A, Mauzerall D. 1982. Absolute absorption cross-sections for photosystem II and the minimum quantum requirement for photosynthesis in Chlorella vulgaris. Biochim Biophys Acta 680:95-106. 
Maranger R, Pullin M. 2003. Elemental complexation by dissolved organic matter in lakes: implications for Fe speciation and the bioavailability of Fe and P. In: Findlay S, Sinsabaugh RL, Eds. Aquatic ecosystems: interactivity of dissolved organic matter. Waltham, MA: Academic Press. p 185-213.

Masojídek J, Grobbelaar J, Pechar L, Koblìzek M. 2001. Photosystem II electron transport rates and oxygen production in natural waterblooms of freshwater cyanobacteria during a diel cycle. J Plankton Res 23:57-66.

Mitchell BG. 1990. Algorithms for determining the absorption coefficient of aquatic particulates using the quantitative filter technique (QFT). Proc SPIE 1302:137-48.

Mitchell BG, Kahru M, Wieland J, Stramska M. 2002. Determination of spectral absorption coefficients of particles, dissolved material and phytoplankton for discrete water samples. In: Mueller JL, Fargion GS, Eds. Ocean optics protocols for satellite ocean color sensor validation. San Diego: Academic Press. p 231-58.

Monteith DT, Stoddard JL, Evans CD, de Wit HA, Forsius M, Høgåsen T, Wilander A, Skjelkvåle BL, Jeffries DS, Vuorenmaa J, Keller B, Kopácek J, Vesely J. 2007. Dissolved organic carbon trends resulting from changes in atmospheric deposition chemistry. Nature 450:537-40.

Morel A, Prieur L. 1977. Analysis of variations in ocean color. Limnol Oceanogr 22:709-22.

Pace ML, Cole JJ. 2002. Synchronous variation of dissolved organic carbon and color in lakes. Limnol Oceanogr 47:333-42.

Parkhill JP, Maillet G, Cullen JJ. 2001. Fluorescence-based maximal quantum yield for PSII as a diagnostic of nutrient stress. J Phycol 37:517-29.

Peterson BJ. 1980. Productivity and the $14 \mathrm{C}-\mathrm{CO}_{2}$ method: a history of the productivity problem. Annu Rev Ecol Syst 11:359-85.

Pinheiro JC, Bates DM. 2000. Mixed-effects models in S and Splus. 1st edn. New York: Springer.

Ralph PJ, Gademann R. 2005. Rapid light curves: a powerful tool to assess photosynthetic activity. Aquat Bot 82:222-37.

Sarkkola S, Nieminen M, Koivusalo H, Laurén A, Kortelainen P, Mattsson T, Palviainen M, Piirainen S, Starr M, Finér L. 2013. Iron concentrations are increasing in surface waters from forested headwater catchments in eastern Finland. Sci Total Environ 463-464:683-9.

Silsbe GM, Kromkamp JC. 2012. Modeling the irradiance dependency of the quantum efficiency of photosynthesis. Limnol Oceanogr 10:645-52.

Skjelkvåle BL, Stoddard JL, Jeffries DS, Tørseth K, Høgåsen T, Bowman J, Mannio J, Monteith DT, Mosello R, Rogora M, Rzychon D, Vesely J, Wieting J, Wilander A, Worsztynowicz A. 2005. Regional scale evidence for improvements in surface water chemistry 1990-2001. Environ Pollut 137:165-76.
Solheim AL, Rekolainen S, Moe SJ, Carvalho L, Phillips G, Ptacnik R, Penning WE, Toth LG, O'Toole C, Schartau A-KL, Hesthagen T. 2008. Ecological threshold responses in European lakes and their applicability for the Water Framework Directive (WFD) implementation: synthesis of lakes results from the REBECCA project. Aquat Ecol 42:317-34.

Steemann-Nielsen E. 1952. On the use of radio-active carbon (C14) for measuring organic production in the sea. Journal du Conseil/Conseil Permanent International pour l'Exploration de la Mer 18:117-40.

Suggett DJ, Moore CM, Geider RJ. 2010. Chlorophyll a fluorescence in aquatic sciences: methods and applications. In: Suggett DJ, Prášil O, Borowitzka MA, Eds. Chlorophyll a fluorescence in aquatic sciences: methods and applications. Dordrecht: Springer. p 103-27.

Tassan S, Ferrari GM. 1995. An alternative approach to absorption measurements of aquatic particles retained on filters. Limnol Oceanogr 40:1358-68.

Tranvik LJ. 1990. Bacterioplankton growth on fractions of dissolved organic carbon of different molecular weights from humic and clear waters. Appl Environ Microbiol 56:1672-7.

Vrede T, Tranvik LJ. 2006. Iron constraints on planktonic primary production in oligotrophic lakes. Ecosystems 9:1094105.

Vähätalo AV. 2009. Light, photolytic reactivity and chemical products. In: Likens GE, Ed. Encyclopedia of inland waters. London: Elsevier Inc.

Vähätalo AV, Salonen K, Münster U, Järvinen M, Wetzel RG. 2003. Photochemical transformation of allochthonous organic matter provides bioavailable nutrients in a humic lake. Archiv für Hydrobiol 156:287-314.

Weyhenmeyer GA, Prairie YT, Tranvik LJ. 2014. Browning of Boreal freshwaters coupled to carbon-iron interactions along the aquatic continuum. PLoS One 9:1-7.

Weyhenmeyer GA, Karlsson J. 2009. Nonlinear response of dissolved organic carbon concentrations in boreal lakes to increasing temperatures. Limnol Oceanogr 54:2513-19. doi:10.4319/lo.2009.54.6_part_2.2513.

Wilhelm C, Becker A, Toepel J, Vieler A, Rautenberger R. 2004. Photophysiology and primary production of phytoplankton in freshwater. Physiol Plant 120:347-57.

Williams PJ, Robertson JE. 1991. Overall planktonic oxygen and carbon dioxide metabolisms: the problem of reconciling observations and calculations of photosynthetic quotients. J Plankton Res 13:153-69.

Williamson C, Morris D. 1999. Dissolved organic carbon and nutrients as regulators of lake ecosystems: Resurrection of a more integrated paradigm. Limnol Oceanogr 44:795-803. 